\title{
DNA Metabarcoding identifies urban foraging patterns of oligolectic and polylectic cavity-nesting bees
}

Kristen Marie Rose Fernandes ( $\checkmark$ Kristen.fernandes@postgrad.curtin.edu.au )

Curtin University Bentley Campus: Curtin University https://orcid.org/0000-0003-3388-5354

Kit Prendergast

Curtin University Bentley Campus: Curtin University

Philip W Bateman

Curtin University Bentley Campus: Curtin University

Benjamin J Saunders

Curtin University Bentley Campus: Curtin University

Mark Gibberd

Curtin University Bentley Campus: Curtin University

Michael Bunce

Curtin University Bentley Campus: Curtin University

Paul Nevill

Curtin University Bentley Campus: Curtin University

Research Article

Keywords: Urbanisation, DNA metabarcoding, native bees, trap-nests, floral preferences

Posted Date: January 18th, 2022

DOI: https://doi.org/10.21203/rs.3.rs-1256295/v1

License: (c) (i) This work is licensed under a Creative Commons Attribution 4.0 International License. Read Full License 


\section{Abstract}

Urbanisation modifies natural landscapes resulting in built-up space and managed green spaces that often substitute native plant species with exotics. Some native bee species have been able to adapt to urban environments, foraging and reproducing in these highly modified areas. However, little is known on how the foraging ecology of native bees is affected by urbanised environments, and whether impacts vary among species with different degrees of specialisation for pollen collection. Here, we aim to investigate the responses of native bee foraging behaviour to urbanisation, using DNA metabarcoding to identify the resources within nesting tubes. We targeted oligolectic (specialist) and polylectic (generalist) cavity-nesting bee species in residential gardens and remnant bushland habitats. We were able to identify 40 families, 50 genera, and 23 species of plants, including exotic species. Oligolectic bee species had higher alpha diversity of plant pollen in their nesting tubes in residential gardens compared to bushland habitats, along with significantly different forage composition between the two habitats. This result implies a greater degree of forage flexibility and urban adaptation for oligolectic bee species than previously thought. In contrast, the richness and composition of plant forage in polylectic bee nesting tubes did not vary between the two habitat types. Our results suggest a complex response of cavity-nesting bees to urbanisation and support the need for additional research to understand how the shifts in foraging resources impact overall bee health.

\section{Introduction}

Within the next century, urban areas around the world will grow rapidly, with some models predicting that by 2100 the global area of urban land will increase to 5.9 times the area that it was in 2000, to cover over 3.6 million $\mathrm{km}^{2}$ of land (Gao and O'Neill 2020). Higher human population density and associated urbanisation can cause the loss of biodiversity and endemic species (McDonald et al. 2018), not only by clearing native vegetation, but by permanently modifying the natural landscape through the creation of built-up space (buildings, roads, and other structures) and managed green spaces (Harrison and Winfree 2015). Even in regions with high biodiversity, such as the southwest of Australia, urban green spaces have a generally higher level of plant diversity than remnant bushland, stemming from the increased planting of exotic species (Prendergast, 2020). This pattern has also been observed in other areas of the globe, such as the United Kingdom (Davies et al. 2009). However, native species relying on the pollen and nectar resources from native plants, may not always be able to access exotic floral resources in urbanised environments. This is because in regions with high endemism and species richness, ecosystem dependencies are common between groups of flora and fauna species (Johnson 2010). Therefore, the clearing of native habitat in these ecosystems due to urbanisation can cause the destabilisation of dependant ecosystem networks, resulting in local extinctions and ecosystem functional collapse (Sánchez-Bayo and Wyckhuys 2019).

Native bees are key components of functional ecosystems. They perform pollinator services across the globe, for both crop and native plant species (Winfree et al. 2008). The survival of native bees in urban areas is dependent on species' ecology and foraging preferences: in some regions, there is evidence of coevolution of bee species with specific native flowering plants (Phillips et al. 2010; Menz et al. 2011), implying that the loss of certain plant groups can have profound impacts on resource availability for their associated visitors. The level of forage flexibility of individual bee species will determine whether: a) the species can access a variety of floral resources (i.e., a generalist) or, b) whether the loss of native flora restricts their foraging availability to a narrower range of the available flora (i.e., a specialist) (Prendergast and Ollerton 2021). For many native bee species, there can also be a preferential avoidance of exotic plant species (Buchholz and Kowarik 2019). Lecty refers to the degree of trophic specialisation for pollen collection (Cane and Sipes 2006). Bees that exhibit specialisation in their diets for pollen from a particular taxon are known as "oligolectic" bees; these bees are believed to be constrained to a narrow resource breadth by physiological, temporal, or environmental factors (Fox and Morrow 1981; Devictor et al. 2010). "Polylectic" bee species, however, can feed on a wide variety of pollen sources.

There is a current lack of available knowledge on floral specialisation for many bee species (Bogusch et al. 2020). To capture the full spectrum of floral resources used by bees requires a combination of foraging observations and pollen analysis from netted bees (Cane and Sipes 2006). Quantification of floral resource usage by many native bees has been largely based on observation data, rather than on pollen collection (Roulston and Cane 2000; Bosch et al. 2009). Additionally, there is some evidence to suggest that lecty is a spectrum, rather than binary, and that resource usage can be varied based on sex or blooming phase of preferred flowering plants (Ritchie et al. 2016). For oligolectic bees, some species have been documented to access nutrition from nectar, floral oils, or pollen from less preferred plants where preferred host plants may be rare or have limited blooming periods (Wcislo and Cane 1996). However, there is still limited understanding of how less preferred forage resources can impact reproduction or overall bee health (Filipiak and Filipiak 2020). Therefore, if conservation actions are needed to protect native bee populations, it is important to understand the preferred foraging resources and the range of forage flexibility of native bees in an area under threat.

Artificial nesting blocks - 'trap nests' or 'bee hotels' - can be beneficial in understanding foraging behaviour of solitary cavity-nesting bees (Maclvor 2017; Staab et al. 2018) and pollen-bee and host-parasitoid interactions between cavity-nesting bee taxa and the surrounding environment (Krombein 1967). Within the cavities, female bees construct brood cells, which they provision with pollen and nectar and then lay an egg. Although not all bee species use trap nests, appropriately designed trap nests can allow for the detection of a wide diversity of bee species, including both males and females of the same species that may not otherwise be observed in field surveys (Prendergast et al. 2020). Additionally, as cavity-nesting bees are central place foragers, the species that use trap nests forage in an area around the nest that is limited by their flight range (Zurbuchen et al. 2010b). This means that cavity-nesting bees can be considered indicators that help understand changes in the local environment (Tscharntke et al. 1998). Thus, studying the larval provisions (nectar and pollen) within trap nests can help build an understanding of forage specialisation for native bees.

As morphological identification of plant materials requires expertise in taxonomic identification across multiple families of plants, genetic tools are being increasingly implemented to aid in pollen identification, primarily DNA metabarcoding (Pornon et al. 2016; Bell et al. 2017). The value of DNA metabarcoding is its ability to identify species accurately and rapidly, which in turn can reveal fine-scale interactions that may not be detected from the observation of pollinator-plant interactions alone (Pornon et al. 2016, 2017). This is especially useful in understanding the impacts of urbanisation on native bees, especially 
in regions where these species may be understudied. DNA metabarcoding works by (i) extracting DNA from environmental or bulk specimen samples, (ii) amplifying the DNA using nucleotide-labelled primers (Bohmann et al. 2021), (iii) sequencing on high-throughput sequencing platforms and identifying the resulting sequences using reference sequence databases (Taberlet et al. 2012) or via taxon-independent approaches (e.g. OTUS). For taxonomic assessment of pollen, metabarcoding has allowed simultaneous identification of plant taxa across multiple species and samples (Taberlet et al. 2012). DNA metabarcoding has been used to identify the taxonomic constituents of pollen loads from pollinators (Pornon et al. 2016, 2017; Bell et al. 2017), brood cells within trap nests (Gresty et al. 2018; Voulgari-Kokota and Ankenbrand 2019), honey (De Vere et al. 2017) and pollen traps at the entrances of beehives (Keller et al. 2015). To our knowledge, DNA metabarcoding has yet to be used to document foraging behaviour and preferences from cavity-nesting bee species in urban environments or in Australian ecosystems.

We used DNA metabarcoding of the biological material from trap nests to investigate how eight species of Australian oligolectic or polylectic cavity-nesting bees utilise forage resources in urban bushland remnants compared to residential gardens. Our hypothesis was that oligolectic species, due to their dependence on a limited range of forage resources will show limited differences in trap nest diversity and composition between the two habitat types, while polylectic bee species that can access a wider range of flora may show a difference.

\section{Materials And Methods Experimental design}

To investigate the impacts of urbanisation on oligolectic and polylectic native bee foraging behaviour, we collected nesting tubes from trap nests from 14 sites across the Perth metropolitan region, in southwest Australia (Figure 1A and B). This region is a known biodiversity hotspot with high levels of species endemism and diversity but it is under threat from various anthropogenic factors, such as urbanisation (Phillips et al. 2010). The 14 sites represented two habitat types: native bushland remnants and residential gardens, seven in each (Fig. 1A). Trap nests and the recorded habitat characteristics used in this study were sourced from a previous study investigating sampling methods for Western Australian native bees (Prendergast et al. 2020). From these trap nests, we examined eight species of native bee that had varying levels of diet specialisation (lecty). Oligolectic bees collect pollen from one plant family (specialists) and polylectic bees collect pollen from a greater diversity of plant families (generalists) (Cane \& Sipes, 2006). Our study included three specialist and five generalist bee species (Table 1). The oligolectic bee species were: Megachile (Hackeriapis) canifrons (Smith, 1853), Megachile (Mitchellapis) fabricator (Smith, 1868), and Rozenapis ignita (Smith, 1853). The polylectic bee species were: Hylaeus (Euprosopis) violaceus (Smith, 1853), Megachile aurifrons (Smith, 1853), Megachile erythropyga (Smith., 1853), Megachile (Hackeriapis) oblonga (Smith, 1879), and Megachile (Hackeriapis) tosticauda (Cockerell, 1912). Where possible, equal numbers of nesting tubes were selected from each habitat type, this ranged from a minimum of 6 to a maximum of 10 nesting tubes for each bee species (Table 1). 
Table 1

Floral host and intertegular span of the eight species of bee included in this study, including number of nesting tubes sampled from each habitat type. Floral hosts were observed through pollinator surveys in both residential gardens and bushland remnant habitats (Prendergast and Ollerton 2021) and surveys by K.S. Prendergast (unpub) in southwest WA. Intertegular span was measured from female body size. Lecty is in terms of known specialisation on pollen in terms of foraging from flower species from a single family for oligolectic bees.

\begin{tabular}{|c|c|c|c|c|c|}
\hline Species & $\begin{array}{l}\text { Intertegular } \\
\text { span (mm) }\end{array}$ & $\begin{array}{l}\text { Lecty } \\
\text { (oligolectic } \\
\text { (specialist) vs } \\
\text { polylectic } \\
\text { (generalist)) }\end{array}$ & Floral host(s) & $\begin{array}{l}\text { Residential } \\
\text { garden }\end{array}$ & $\begin{array}{l}\text { Bushland } \\
\text { remnant }\end{array}$ \\
\hline $\begin{array}{l}\text { Megachile } \\
\text { (Hackeriapis) } \\
\text { canifrons (Smith, } \\
\text { 1853) }\end{array}$ & 3.17 & Oligolectic & Jacksonia sternbergiana, J. furcellata, and Verticordia plumosa† & 10 & 10 \\
\hline $\begin{array}{l}\text { Megachile } \\
\text { (Mitchellapis) } \\
\text { fabricator } \\
\text { (Smith, 1868) }\end{array}$ & 3.57 & Oligolectic & Jacksonia sternbergiana and J. furcellata & 6 & 9 \\
\hline $\begin{array}{l}\text { Rozenapis ignita } \\
\text { (Smith, 1853) }\end{array}$ & 3.25 & Oligolectic & Jacksonia sternbergiana, J. furcellata, and Corymbia calophylla† & 10 & 10 \\
\hline $\begin{array}{l}\text { Hylaeus } \\
\text { (Euprosopis) } \\
\text { violaceus (Smith, } \\
1853 \text { ) }\end{array}$ & 1.76 & Polylectic & $\begin{array}{l}\text { Melaleuca preissiana, M. huegelii, M. teretifolia, Eucalyptus spp., and } \\
\text { Banksia sessilis }\end{array}$ & 9 & 8 \\
\hline $\begin{array}{l}\text { Megachile } \\
\text { aurifrons (Smith, } \\
\text { 1853) }\end{array}$ & 2.58 & Polylectic & $\begin{array}{l}\text { Scaevola spp., Plectranthus spp., Jacksonia furcellata, J.sternbergiana, } \\
\text { Melaleuca quinquenervia, and Babingtonia camphorosmae }\end{array}$ & 10 & 10 \\
\hline $\begin{array}{l}\text { Megachile } \\
\text { erythropyga } \\
\text { (Smith., 1853) }\end{array}$ & 3.2 & Polylectic & $\begin{array}{l}\text { Scaevola spp., Plectranthus spp., Corymbia calophylla, and Callistemon } \\
\text { spp. }\end{array}$ & 10 & 10 \\
\hline $\begin{array}{l}\text { Megachile } \\
\text { (Hackeriapis) } \\
\text { oblonga (Smith, } \\
\text { 1879) }\end{array}$ & 2.42 & Polylectic & $\begin{array}{l}\text { Corymbia callophylla, Goodenia filiformis, Jacksonia sericea, Melaleuca } \\
\text { huegelii, Babingtonia camphorosmae, Cassytha racemosa, Stylidium } \\
\text { brunonianum, Asartea scoparia, Baekea spp., Thryptomene saxicola, and } \\
\text { Mentha pulegium }\end{array}$ & 10 & 10 \\
\hline $\begin{array}{l}\text { Megachile } \\
\text { (Hackeriapis) } \\
\text { tosticauda } \\
\text { (Cockerell, 1912) }\end{array}$ & 2.37 & Polylectic & $\begin{array}{l}\text { Babingtonia camphorosmae, Corymbia callophylla, Billardiera variifolia, } \\
\text { Baekea spp., and Cassytha racemosa }\end{array}$ & 7 & 9 \\
\hline
\end{tabular}

\section{Habitat Characteristics and Native Bee Observations}

We used the following habitat characteristics and pollinator survey data sets gathered from Prendergast et al. (2020) and Prendergast and Ollerton (2021) at each of the 14 sites to distinguish between remnant bushland and residential gardens: total number of bees including honey bees; native bee richness; the number of honey bees; the number of native bees; the proportion of native bees to introduced bees in both richness and number; bare ground cover (a proxy for nesting space for ground-nesting bee species); the number of woody plants (a proxy for nesting material for cavity-nesting bee species); the total area of the site; percentage of built space; native floral species richness; the number of native flowers; and the proportion of native flowers to horticultural species both in richness and in number (for descriptions see Supp Table 2). 
Table 2

Analysis of variance results for plant species detected through metabarcoding showing Habitat $\mathrm{x}$ Bee Species interaction with square-root transformed Observed Richness and Species composition between individual bee species and habitat types (Residential Gardens vs Remnant Bushland). P-Adj values are with a post-hoc Bonferroni-Holms correction applied due to multiple comparisons. * Indicates

\begin{tabular}{|c|c|c|c|c|c|c|c|}
\hline \multirow{3}{*}{ Species } & \multirow{3}{*}{$\begin{array}{l}\text { Lecty } \\
\text { (oligolectic (specialist) vs polylectic (generalist)) }\end{array}$} & \multicolumn{3}{|c|}{ Observed Richness } & \multicolumn{3}{|c|}{ Species Composition } \\
\hline & & t value & $P$ value & P-Adj & $\mathrm{t}$ value & $P$ value & P-Adj \\
\hline & & & & & & & \\
\hline Megachile canifrons & Oligolectic & 11.383 & $0.006^{*}$ & $0.042^{\star}$ & 1.753 & $0.039 *$ & 0.156 \\
\hline Megachile fabricator & Oligolectic & 19.764 & $0.001 *$ & $0.008^{*}$ & 3.624 & $0.001^{\star}$ & $0.007 *$ \\
\hline Rozenapis ignita & Oligolectic & 2.186 & 0.156 & 0.936 & 3.128 & $0.000^{\star}$ & $0.000 *$ \\
\hline Hylaeus violaceus & Polylectic & 0.776 & 0.396 & 1.000 & 1.555 & 0.089 & 0.267 \\
\hline Megachile aurifrons & Polylectic & 0.327 & 0.575 & 1.000 & 2.440 & $0.001^{\star}$ & $0.007 *$ \\
\hline Megachile erythropyga & Polylectic & 0.719 & 0.421 & 1.000 & 1.718 & $0.011^{\star}$ & 0.055 \\
\hline Megachile oblonga & Polylectic & 2.097 & 0.175 & 0.936 & 1.413 & 0.102 & 0.267 \\
\hline Megachile tosticauda & Polylectic & 0.010 & 0.922 & 1.000 & 1.559 & 0.101 & 0.267 \\
\hline
\end{tabular}

Floral hosts for each species were designated based on observations of bees foraging on flowers across southwest WA from 2016 - 2021 by K. S. Prendergast (unpub) and, if present, records in Houston (2000). Intertegular span (Cane 1987) was measured from dorsal stacked photos of a female of each species (Canon DLSR, 100mm lens, 1:1 magnification, f-stop 8). The images were imported into Adobe Photoshop and measured using the set measurement scale and ruler features. Intertegular span is the distance between the points where the wings attach to the thorax. It has been used as an estimate of bee size and flight abilities (Cane 1987). Greater intertegular span is a proxy for greater potential foraging distance (Wright et al. 2015). The largest bee species in our study was the oligolectic Megachile (Mitchellapis) fabricator, and the smallest species was the polylectic Hylaeus violaceus (Table 1).

\section{Sample Processing}

Once young bees had emerged from nesting tubes, each tube was separated by site and species, constituting a sample. In total, we sampled 148 nesting tubes. Where possible, equal numbers of nesting tubes were selected for each species from each habitat type (ranging from five to ten tubes per habitat type) (Table 1). Sterilised forceps were used for each sample to scrape the insides of nesting tubes of frass (larvae faecal matter), pollen and, for some species, resin debris (Fig. 1C). Scrapings were then homogenised using a PreCellLys $242.8 \mathrm{~mm}$ Ceramic Bead Kit and a Minilys Personal Homogeniser for 3 minutes at 5000 rpm (Bertin Instruments, France)

\section{DNA extraction, PCR Amplification, and Sequencing}

DNA extraction was conducted using a DNeasy Plant Mini Kit on an automated Qiacube (Qiagen, Netherlands) modified with a $450 \mu \mathrm{L}$ starting volume of digest and a $100 \mu \mathrm{L}$ elution volume. Negative extraction controls were included for every 48 samples $(n=4)$.

Two plant metabarcoding assays were used to analyse the bee nesting tube contents across two gene regions of varying lengths. A shorter assay of $\sim 30-143$ bp targeting the P6 loop of the chloroplast trnL (UAA) intron (primers g and h; Taberlet et al. 2007) and a longer 563 bp ITS2 assay (ITS2_S2F/S3R; Chen et al. 2010). Quantitative PCR (qPCR) was carried out on all samples to assess the amplification efficiency and presence of PCR inhibitors using serial dilutions of undiluted, 1:10 and 1:100. qPCR reactions were carried out in $25 \mu \mathrm{l}$ reactions containing: $1 \mathrm{U}$ of $\mathrm{AmpliTaq}_{\text {gold, }} 1 \times \mathrm{PCR}_{\mathrm{Gold} \mathrm{Buffer} \text { and } 2 \mathrm{mM} \text { MgCl }}$ (all from Applied Biosystems, USA), $0.4 \mathrm{mg} / \mathrm{mL}$ bovine serum albumin (Fisher Biotec, Australia), $0.25 \mathrm{mM}$ dNTPs (Astral Scientific, Australia), $0.4 \mu \mathrm{M}$ of each forward and reverse primer, $0.6 \mu \mathrm{L}$ of $1 / 1000$ SYBR Green (Invitrogen, USA), and $2 \mu \mathrm{L}$ of template DNA. The qPCR conditions for trnL were as follows: $95^{\circ} \mathrm{C}$ for 5 minutes, followed by 45 cycles of $95^{\circ} \mathrm{C}$ for $30 \mathrm{~s}, 52^{\circ} \mathrm{C}$ for $30 \mathrm{~s}$, and $72^{\circ} \mathrm{C}$ for $45 \mathrm{~s}$, with a final elongation at $72^{\circ} \mathrm{C}$ for 10 minutes. For ITS2, the qPCR conditions were as follows: $94^{\circ} \mathrm{C}$ for 5 minutes, followed by 45 cycles of $94^{\circ} \mathrm{C}$ for $30 \mathrm{~s}, 56^{\circ} \mathrm{C}$ for $30 \mathrm{~s}$, and $72^{\circ} \mathrm{C}$ for $45 \mathrm{~s}$, with a final elongation at $72^{\circ} \mathrm{C}$ for 10 minutes. Negative extraction, qPCR and positive (Brassica oleracea, cauliflower DNA) controls were also included in the reactions.

Following qPCR, dilutions that showed the optimal level of amplification (template amount relative to any inhibition), were amplified with 'fusion primers', which are gene-specific primers labelled on both the forward and reverse with 6-8bp molecular identification (MID) tags coupled to Illumina sequencing adaptors. Each sample was tagged with a unique combination of forward and reverse MID tags not previously used within the laboratory, and qPCR reactions were prepared in an ultra-clean laboratory free from extracted or amplified DNA to minimise the possibility of contamination. Samples were amplified in duplicate using the qPCR conditions mentioned above to reduce the effects of PCR stochasticity (Murray et al. 2015). This included extraction and qPCR negative controls, but not qPCR positive controls. Using the qPCR results, PCR products were pooled in approximate equimolar concentration pools based on amplification curves, including negative controls. Pools were then quantified using a QIAxcel Advanced System (Qiagen) with the QIAxcel DNA High-Resolution Kit. As per the results of the quantification, sample pools were then combined in approximate equimolar ratios to create a sequencing library for each assay (trnL and ITS2). The trnL library was size-selected using a Pippin Prep 2\% agarose Marker B cassette (Sage Science, USA) for fragments between 160-450bp long, and the ITS2 library was size-selected for 200-650bp on a Pippin Prep 1.5\% Marker K cassette (Sage Science). Library pools were then purified using a QIAquick PCR purification kit (Qiagen) as per the manufacturer's instructions with the addition of a 5-minute incubation at room temperature before elution. The purified library was eluted in $40 \mu$ and quantified with a QuBit (Invitrogen, USA) using double-stranded DNA high-sensitivity reagents to determine the 
optimal volume of the library required for sequencing. Both libraries were sequenced on an Illumina MiSeq (Illumina, USA). The trnL libraries were sequenced on a single-end 300 cycle V2 kit, and the ITS2 libraries were sequenced on a paired-end 600 cycle V3 kit as per the manufacturer's directions.

\section{Bioinformatics and Sequence Processing}

Unidirectional and unmerged paired-end sequencing reads were demultiplexed (assigned to their appropriate sample using the MID-tag combos) using 'Obitools' (Boyer et al. 2016) for the trnL dataset. To retain the paired-end data in the ITS2 dataset as unmerged reads for analysis using the 'DADA2' package (Callahan et al. 2016), demultiplexing was carried out using the default parameters in the 'insect' package (Wilkinson et al. 2018 ) in R v 3.6.1 (R Core Team 2019). Sequencing data was then quality filtered (trnL: minimum length $=50$, maximum expected error $=2$, no ambiguous nucleotides; ITS2: minimum length= 100 , maximum expected error $=2$, no ambiguous nucleotides), denoised, with paired-end reads (ITS2) merged with a minimum overlap length of 12 , sequences identified as chimeras removed, and then dereplicated using the 'DADA2' package (Callahan et al. 2016) to produce Amplicon Sequence Variants (ASVs). ASVs were then curated using the 'LULU' package at default parameters (Frøslev et al. 2017). ASVs were matched to the NCBI GenBank reference database (www.ncbi.nlm.nih.gov/genbank/) using the Basic Local Alignment Search Tool (BLAST) for taxonomic assignment on a high-performance cluster computer (Pawsey Supercomputing Centre). BLAST results returned the top 10 hits with a minimum query coverage of $95 \%$ and a minimum percentage identity of $85 \%$. Taxonomic assignments were made to the lowest common ancestor (LCA) using MEGAN (METAGenome Analyser v 6.13.5 (Huson 2018)) with a minimum score of 50 for $t r n L$ and 150 for ITS2. Plant taxa were cross-referenced to the Atlas of Living Australia (www.ala.org.au) and plant surveys of the sites (Prendergast and Ollerton 2021).

To determine the plant communities associated with the bee nesting tubes, only ASVs identified as plants (Phylum: Streptophyta) were retained in the analysis. ASV tables from both markers were then combined, retaining their ASV identity from each assay independent of taxonomy. Further filtering was then carried out on the entire data set. Any ASVs present in the negative control samples were removed using the 'phyloseq' package (McMurdie and Holmes 2013). Using the combined ASV table, a $0.05 \%$ minimum abundance filtering threshold was set within each sample to combat false, low abundance ASVs from each sample across with R 3.6.1 (R Core Team 2019). Minimum abundance filtering is equivalent to conducting rarefaction on the dataset without the need to remove low abundance samples (Prodan et al. 2020). Using 'phyloseq' (McMurdie and Holmes 2013), low occurrence ASVs with less than 5 sequences and occurring in only one sample were also removed. We removed any samples with less than 12,000 reads as this was where most samples had reached asymptote on a rarefaction curve (Supp Fig. 1).

\section{Statistical Analysis}

To establish the differences between the two different habitat types, a PERMANOVA (fixed factor of 'habitat' with two levels: 'residential garden' and 'bushland remnant') was conducted on normalised habitat characteristic values outlined above with Euclidian distance and 9999 permutations using the PERMANOVA+ add on (Anderson et al. 2008) for PRIMER 7 (Clarke and Gorley 2015). Co-linear variables with a correlation of greater than 0.95 were excluded from the analysis. The number of flowers and number of native flowers were found to be co-linear $(r=0.96)$ and thus, only the number of flowers were included in the analysis. A Principal Coordinate Analysis (PCO) based on Euclidian distance was performed on the normalised data from the measured habitat characteristics. The relative contribution of each habitat characteristic to the differences between habitat types was evaluated using the strength of the correlation coefficient to the PCO axes. Where habitat characteristics had a correlation $\geq 0.5$ to the PCO axes, vectors were plotted to illustrate the strength and direction of the association.

Statistical analysis on sequencing data was performed using R 3.6.1 (R Core Team 2019) and PRIMER 7 (Clarke and Gorley 2015). The ASV abundance matrix was converted to presence-absence data, and all plant community statistics were calculated from this matrix. Alpha diversity was calculated using the 'phyloseq' package (McMurdie and Holmes 2013). Alpha diversity was square-root transformed (to meet normality for analysis of variance) and compared using a Fully Factorial Orthogonal Analysis of Variance (ANOVA) with species of bee and habitat as factors. A Pearson correlation test was also conducted on the observed plant ASV richness and the number of nesting tubes using R 3.6.1 (R Core Team 2019).

Plant community composition was compared in the same way with a Permutational Analysis of Variance (PERMANOVA) using Jaccard similarity with 9999 permutations using the PERMANOVA+ add on (Anderson et al. 2008) for PRIMER 7 (Clarke and Gorley 2015). The multivariate dispersions around the centroid for habitat was tested for each of the bee species using the PERMDISP function in the PERMANOVA+ add on (Anderson et al. 2008) for PRIMER 7 (Clarke and Gorley 2015). Plant community composition clustering was illustrated with Non-metric Multidimensional Scaling (NMDS) using Jaccard Similarity with the 'vegan' package (Oksanen et al. 2019) and 'ggplot2' (Wickham 2016). Similarity percentage analysis (SIMPER) was used to identify significant plant families responsible for the differences between habitat type using PRIMER 7 (Clarke and Gorley 2015) based on the ASVs that could be identified to a family level.

\section{Results}

\section{Residential Gardens and Remnant Bushland Habitats}

There was a significant difference between the habitat types (residential garden and bushland remnant) based on the measured habitat characteristics (PERMANOVA, $F_{(1,131)}=43.65$, p <0.001). PCO showed that $47.4 \%$ of the variation among the two habitat types was explained by axes 1 and 2 (Fig. 2). Residential gardens were associated with a greater percentage of built space and floral species richness, whilst remnant bushland was associated with the greater richness and abundance of native plant flowers and bee species, woody plants, and bare ground.

\section{Sequencing Results}

The $t r n L$ and the ITS2 assays generated 8,949,032 (mean $=113,114 \pm 812$ SE sequences per sample) and 17,419,536 (mean $=72,646 \pm 501$ SE sequences per sample) quality filtered and 'LULU'-curated sequences, respectively. Only six ASVs were detected within the negative control samples, two from the ITS 2 assay 
and four from the trnL assay. As per Bell et al. (2017), these signified low levels of contamination either in the reagents or from sampling/laboratory workflows as the ASVs were from a subset of some of the most common taxa detected (Myrtaceae spp. and Fabaceae spp.). These ASVs were removed from further analysis. Analysis was then conducted on 14,521,974 sequences from 213 ASVs and 115 samples.

In total there were 40 families, 50 genera, and 23 species of terrestrial vascular plants detected through metabarcoding of the bee nesting tubes. The majority of the metabarcoding detections belonged to the family Myrtaceae (103 ASVs), followed by Fabaceae (23 ASVs), Poaceae (10 ASVs) and Asteraceae (10 ASVs). There were several plant families detected through metabarcoding of the nesting tubes that were not observed as floral-hosts in plant-pollinator surveys within the same geographic region (Table 1). These families include both native and exotic plant species (Supp Fig. 2, Supp Table 3) that are either native to the area or can be found in residential gardens or road-side verges. Here we define exotic plants as those that are exotic to Australia.

Both assays performed similarly at higher taxonomic levels, at least $99.1 \%$ of ITS2 ASVs and $88.7 \%$ of trnL ASVs were able to be identified to family level. This was markedly reduced at finer taxonomic levels for the $t r n$ L assay where only $43.9 \%$ of ASVs could be identified to genus level while $97.4 \%$ of ITS2 ASVs could be identified to genus level; however, this was predominantly Eucalyptus ASV detections. At a species level, both assays performed similarly with $29.6 \%$ of the ITS2 ASVs identified to species and $23.5 \%$ of $t r n L$ ASVs identified to species. Even though the trnL assay had a limited taxonomic resolution, it detected a broader range of plant families (36) than the ITS2 assay (15), with 10 plant families shared between the two (Supp Fig. 2). For both ITS2 and trnL there was a higher relative sequence abundance (from presence-absence data) from the Myrtaceae family than any other plant family within the dataset (Supp Fig. 2).

However, whilst the ITS2 data was dominated by Myrtaceae sequences, the trnL dataset showed higher proportions of other families, such as Fabaceae (Supp Fig. 2).

\section{Native bee nest provision in residential gardens and urban bushland fragment habitats}

There was no significant ( $p=0.62$ ) correlation between sampling effort (number of nesting tubes) and the observed plant ASV richness. A fully factorial, twoway ANOVA on the square-root transformed observed ASV richness showed a significant interaction of habitat type and bee species $\left(F_{(7,98)}=2.91\right.$, $\left.p<0.01\right)$ and an overall effect of habitat type $\left(\mathrm{F}_{(1,98)}=6.72, \mathrm{p}=0.011\right)$, but not of bee species $\left(\mathrm{F}_{(7,98)}=1.99, \mathrm{p}=0.064\right)$. Within the interaction, only $M$. canifrons and $M$. fabricator nest contents had significantly different ASV richness between habitat types (Table 2). These were both oligolectic (specialist) species. For both species, square-root transformed richness in the residential garden habitat type was higher than the bushland habitat type (Fig. 3A). Between the habitat types, residential gardens had a higher observed square-root transformed ASV richness (mean $6.06 \pm 0.2 \mathrm{SE}$ ) than bushland habitat types (mean $=5.57 \pm 0.12 \mathrm{SE}$ ).

The results of PERMANOVA on the composition of plant ASVs in nesting tubes found that there was a significant interaction of bee species and habitat type $\left(F_{(7,98)}=1.971, p<0.001\right)$, and also differences between habitat type $\left(F_{(1,98)}=5.769, p<0.001\right)$ and bee species $\left(F_{(7,98)}=3.292\right.$, $\left.p<0.001\right)$. Investigating the significant interaction between habitat type and species found a significant difference in the composition of plant taxa ASVs detected from residential garden and bushland nesting tubes for all the oligolectic species (M. canifrons, M. fabricator, and R. ignita) but only two of the polylectic species (M. erythropyga and M. aurifrons) (Table 2).

Analysis of multivariate dispersions indicated no significant difference in the diversity of forage between residential gardens and bushland remnants for most bee species ( $p>0.05)$. The exception was the polylectic species $M$. oblonga $\left(F_{(1,15)}=6.562, p=0.021\right)$, with forage ASVs in the Residential Gardens being less variable ( mean dispersion $46.76 \pm 1.68 \mathrm{SE}$ ) than in the Bushland Remnants ( $52.74 \pm 1.61 \mathrm{SE}$ ).

SIMPER analysis indicated that Myrtaceae and Fabaceae were the most common detections in residential gardens and bushland remnant habitat types (Supp Table 1). This was to be expected as Myrtaceae and Fabaceae were the most common plant families detected across the dataset (Supp Fig. 2). Results from the SIMPER analysis based on the plant families of detected ASVs indicated that there was an observed decrease in the frequency of Fabaceae ASVs contributing to the similarity within residential gardens (Supp Table 1).

\section{Discussion}

Our study showed that eDNA metabarcoding can reveal the contents of nesting tubes, using eight native, cavity-nesting bee species in bushland remnants and residential gardens in Western Australia. Contrary to our hypothesis, two of our three oligolectic (specialist) bee species showed significantly higher species richness of plant hosts in residential gardens than in bushland remnant sites, and all our oligolectic species showed significantly different forage composition between habitat types. In comparison, there was no significant difference in richness or forage composition for the majority of polylectic bee between habitat types, derived from the nesting tubes. This suggests a much more complex response of native bee species to urbanisation than previously thought.

\section{Urban adaptation and forage flexibility for oligolectic bee species}

Contrary to our hypothesis, the oligolectic bee species, $M$. canifrons and $M$. fabricator, were the only study species with significantly different ASV richness between habitat types, with higher richness observed in the residential gardens. There are several potential explanations for this. Higher diversity could indicate greater availability of forage in these habitat types for native bees, although, considering the co-evolution of native bees to their native host plants (Houston 2000; Phillips et al. 2010) and that both these species are oligolectic, this seems unlikely. Instead, we suggest that this is an indicator of lower availability of preferred resources. This was supported by the increase in similarity of forage composition within residential gardens for these bees. As a result, we suggest that even specialist native bees can expand their diet breadth to meet their resource requirements in suboptimal habitats. It should be noted that these oligolectic bee species were chosen as they were commonly found in our residential garden and remnant bushland study sites and therefore allowed us to achieve an adequate sampling size. As such, these species could be considered 'urban adapters' (McKinney 2002) in these spaces, as they are able to forage and reproduce efficiently enough to allow populations to be maintained. This is supported by previous observations in these same residential garden sites, where native bees would visit native plants even if they were not native to the local area (Prendergast and Ollerton 2021). The foraging behaviour of the

Page $7 / 14$ 
oligolectic bee species in urban environments in our study therefore represents an adaptation to these habitats. However, we have not studied the 'urban avoider' (McKinney 2002) oligolectic species that cannot survive in areas without their preferred resources, and thus these species may be more at risk of decline as a result of urbanisation.

The oligolectic bee species also had a generally larger intertegular span than did the polylectic species in this study, such that they can theoretically fly farther (Wright et al. 2015) to meet resource requirements. They may therefore be able to increase the diversity of their forage, as reflected by the contents of the nesting tubes. With residential gardens in our study characterised by higher floral richness and increased built space than bushland remnants, this could mean that these larger oligolectic bees were able to navigate through these spaces to find adequate forage resources. This is supported by previous research where bee communities in urbanised, fragmented vegetation were dominated by bee species with a greater flight range than in nature reserve areas (Hung et al. 2019). However, longer flight distance to forage for resources may reduce fitness of solitary bees by reducing their offspring production (Zurbuchen et al. 2010a) and lifespan due to the wear and stress posed on the exoskeleton and flight muscles (Torchio and Tepedino 1980). While these oligolectic bees may survive in urban areas, there may be unknown physiological and reproductive consequences to living in urbanised areas that could impact the overall health of these bee populations.

In contrast, most of our polylectic bee species, except for $M$. aurifrons, showed no significant differences in the forage composition between habitat types. Although there are more exotic plant species in residential gardens than in bushland fragments, residential gardens were not devoid of native flowering plant species (Prendergast 2020). This suggests that the generalist bee species can access the same range of forage in residential gardens that they would in bushland remnants. These results reflect those of Buchholz et al. (2020) who found that urbanisation leads to an increase in the number of polylectic bee species. However, even though the polylectic bee species M. oblonga showed no significant difference in the ASV richness and composition of its forage between habitat types, there was significantly smaller dispersion observed for the ASVs in the residential gardens than in the bushland habitats. This indicates reduced diversity of forage availability for this species in urban areas. Similarly, our oligolectic bee species with significant differences in forage richness between habitat types also demonstrated a significant difference in the composition of forage in nesting tubes. A significant difference in composition could indicate that these bee species are able to access the varying resources - exotic or horticultural native plant species - available in urban environments, even if these foraging sources may not be preferred. Further, the distinction between urban and bushland environments in forage resources, especially for oligolectic bees, can suggest that these species are having to change their foraging behaviour to a higher degree than the polylectic species that showed no effect.

For both the oligolectic M. canifrons and M. fabricator, composition of forage resources in nesting tubes was characterised by Eucalyptus ASVs (family Myrtaceae), which is a common native genus and frequent in horticultural plantings (Prendergast and Ollerton 2021). Myrtaceae ASVs also contributed to a significant percentage of the similarity in residential gardens, potentially in the absence of preferred Fabaceae forage. Whilst $M$. canifrons and $M$. fabricator are Fabaceae specialists, lecty specialisation refers to pollen specialisation (Cane and Sipes 2006); it may be that these additional plant species recorded in the specialist bees' tubes represent smaller amounts of pollen present in nectar sources. One of the limitations of the current methods in that they cannot accurately quantify the relative proportions of plant species present, nor determine whether the sources were derived from nectar or pollen foraging. Further, these detections could also represent resin gathered from Eucalyptus trees to create partitioning between brood cells in nesting tubes (Houston 2000). Additional research is required to determine the fitness consequences, if any, of how these differences in pollen diversity and composition in nesting tubes affect the native bee progeny (Filipiak and Filipiak 2020).

\section{DNA metabarcoding for taxonomic identification of plants}

Prior studies have shown that DNA metabarcoding of pollen samples is simpler and provides greater taxonomic resolution than does traditional palynological approaches (Galimberti et al. 2014; Bell et al. 2017). However, this approach is not without limitations. Assays targeting shorter DNA fragments have been recommended for metabarcoding studies because this DNA can be heavily degraded (Taberlet et al. 2007, 2012), but short fragments may lack the resolving power to discriminate at finer taxonomic levels (Pornon et al. 2016). The ITS2 region has been previously suggested as a useful region for molecular identification of eukaryotes because it has fairly conserved regions across many taxonomic groups and contains a great deal of variability to distinguish closely related species (Chen et al. 2010; Yao et al. 2010). Nevertheless, both the assays used in our study showed limited species level identification. This might also be explained by inadequate taxonomic representation in reference databases (Gous et al. 2021), which are limited for many floral taxonomic groups in Australia (Dormontt et al. 2018). These findings support the need for increased coverage of reference databases across a variety of Australian plant taxonomic groups to aid molecular taxonomic assignment (Bell et al. 2016).

The shorter trnL assay ( 30-143 bp) detected a much wider range of plant families than did the ITS2 assay ( 563 bp), which could suggest that larval digestion or other environmental factors may have degraded the eDNA and thus favours short amplicons. Dietary analysis using ITS2 plant assays is somewhat problematic as the amplicon length is too large to be reliably detected in degraded dietary items (Moorhouse-Gann et al. 2018). Further, interpretation of ITS2 data presents a challenge because of paralogous gene copies (Hollingsworth et al. 2011; Moorhouse-Gann et al. 2018), which may be a particular issue for eucalypts (Bayly et al. 2008). The ITS2 assay had very high numbers of Eucalyptus ASVs, which appeared to amplify in our samples preferentially. Thus, there needs to be a balance between taxonomic resolution and taxonomic breadth when choosing assays for metabarcoding studies. Therefore, we suggest a multi-assay approach, such as ours, to better distinguish plant communities from insect-gathered pollen (Pornon et al. 2016). Additionally, the ongoing development of group-specific (e.g. family) assays may help complement the use of assays such as ITS2 and trnL whose role is to provide a high-level assessment.

While there are no known visual observations of any of the cavity-nesting bee species in our study foraging on members of Poaceae (Houston 2000; Prendergast 2020; Prendergast and Ollerton 2021), Poaceae ASVs were detected from 48 out of the 114 samples, equally among bee species and habitat types. In addition, a recent study that used metabarcoding of pollen from Australian native beehives similarly found unexpected detections of Poaceae (Wilson et al. 2021). Although Wilson et al. (2021) suggest that these detections represent actual foraging activity, the results from the previous pollinator surveys at the sites in our study (Prendergast 2020; Prendergast and Ollerton 2021) do not support this hypothesis. Additionally, Poaceae constitutes a large 
proportion of total airborne pollen (Brennan et al. 2019). This suggests that Poaceae detections in our samples may instead result from environmental accumulation and is detected through the sensitivity of the DNA metabarcoding methodology. Likewise, we cannot discern whether the detection of exotic plant ASVs from the nesting tubes represents actual foraging activity or background environmental accumulation. Previous observations from pollinator surveys showed no interactions between native bee species and exotic plants (Prendergast 2020; Prendergast and Ollerton 2021). Still, pollinator surveys undertaken through visual observation can be affected by bias based on observer, method, and context (O'Connor et al. 2019). Therefore, these exotic plant detections from nesting tubes represent directions for future research to explore the value of exotic plant species as a foraging resource for endemic native bees. For example, collection of data across different seasons to explore the persistence of the signal, and/or dissection of gastro-intestinal tracts directly from bees to avoid environmental background from the nesting tubes.

Our finding of a differential response of oligolectic and polylectic bee species to urbanisation adds to growing recognition that not all bees respond uniformly to ecosystem changes (Banaszak-Cibicka and Żmihorski 2012; Rader et al. 2014; De Palma et al. 2015). The bee species in our study were chosen as polylectic and oligolectic species that readily use urban environments. The oligolectic bee species in our study demonstrated a shift from their preferred forage in bushland remnants to forage that was available in residential gardens. This same shift was not observed for polylectic species. Therefore, these species represent urban adapters in this region, with a degree of plasticity in their foraging preferences and resources. The shift in these resources currently has unknown future impacts for the health of bee species in urbanised areas. Previous work on cavity-nesting bees advocates for increasing the diversity of native forage available, especially in anthropogenically impacted landscapes (Gresty et al. 2018). However, there is little knowledge available on species-specific ecology and preferred host plants in urban environments for many Australian bee species, as most studies have been conducted in Europe or the Americas (Staab et al. 2018; Wenzel et al. 2020). Although studies on Australian native bees are increasing (Threlfall et al. 2015; Prendergast and Ollerton 2021; Prendergast et al. 2021), it is still imperative to continue research into the natural history of bee species here and around the globe. The use of DNA metabarcoding can provide a valuable complement to these studies through the ability to rapidly identify the composition of forage resources collected by bees. As areas become more urbanised, future research on the impacts that changes in forage availability and composition have on the health and reproduction of native bees will be invaluable in conserving native bee populations. Such research builds upon our knowledge of which species will be able to adapt to urban environments, and which will completely avoid these areas. It is important that a more nuanced approach is taken to studying foraging preferences. Our results support the idea that lecty is a spectrum than a strict dichotomy (Ritchie et al. 2016) and we suggest a more flexible approach to this categorisation in the future. This will be an especially important consideration when examining the impacts of threats to native bee species and designing interventions to mitigate these threats.

\section{Declarations}

\section{Acknowledgements}

This work was supported by computational resources provided by the Pawsey Supercomputing Centre with funding from the Australian Government and the Government of Western Australia. KF was partially supported by funding from Food Agility CRC Ltd, funded under the Commonwealth Government CRC Program. KP was supported by a Forrest Research Foundation Scholarship. We would like to acknowledge Kristine Bohmann for their helpful comments and advice in drafting the manuscript.

Funding: KF was partially supported by funding from Food Agility CRC Ltd, funded under the Commonwealth Government CRC Program. KP was supported by a Forrest Research Foundation Scholarship.

Conflict of Interest. The authors have no conflicts of interest to declare.

Ethics approval: Not applicable

Consent to participate: Not applicable

Consent for publication: Not applicable

Availability of data and material: Sequencing data, Bioinformatic scripts, and sample information can be found at: 10.5281/zenodo.5564128

Code availability: Not applicable

Author Contributions: KF, KP, MG, MB, and PN conceptualised the study. KP supplied the samples. KF conducted the experimentation and analysis. BJS assisted with statistical analysis. KF wrote the original draft of the manuscript. All authors contributed to review and editing of the manuscript.

\section{References}

1. Anderson M, Gorley R, Clarke KP (2008) PERMANOVA+ for PRIMER: guide to software and statistical methods. PRIMER-E Ltd.

2. Banaszak-Cibicka W, Żmihorski M (2012) Wild bees along an urban gradient: winners and losers. J Insect Conserv 16:331-343. https://doi.org/10.1007/s10841-011-9419-2

3. Bayly MJ, Udovicic F, Gibbs AK, Parra-O C, Ladiges PY (2008) Ribosomal DNA pseudogenes are widespread in the eucalypt group (Myrtaceae): implications for phylogenetic analysis. Cladistics 24:131-146. https://doi.org/10.1111/j.1096-0031.2007.00175.x

4. Bell KL, de Vere N, Keller A, Richardson RT, Gous A, Burgess KS, Brosi BJ (2016) Pollen DNA barcoding: current applications and future prospects. Genome 59:629-640. https://doi.org/10.1139/gen-2015-0200 
5. Bell KL, Fowler J, Burgess KS, Dobbs EK, Gruenewald D, Lawley B, Morozumi C, Brosi BJ (2017) Applying Pollen DNA Metabarcoding to the Study of Plant-Pollinator Interactions. Appl Plant Sci 5:1600124. https://doi.org/10.3732/apps.1600124

6. Bogusch P, Bláhová E, Horák J (2020) Pollen specialists are more endangered than non-specialised bees even though they collect pollen on flowers of non-endangered plants. Arthropod Plant Interact 14:759-769. https://doi.org/10.1007/s11829-020-09789-y

7. Bohmann K, Elbrecht V, Carøe C, Bista I, Leese F, Bunce M, Yu DW, Seymour M, Creer S (2021) Strategies for sample labelling and library preparation in DNA metabarcoding studies. Authorea Preprints. https://doi.org/10.22541/au.162141261.10649593/v1

8. Bosch J, Martín González AM, Rodrigo A, Navarro D (2009) Plant-pollinator networks: adding the pollinator's perspective. Ecol Lett 12:409-419. https://doi.org/10.1111/j.1461-0248.2009.01296.x

9. Boyer F, Mercier C, Bonin A, Le Bras Y, Taberlet P, Coissac E (2016) obitools: A unix-inspired software package for DNA metabarcoding. Mol Ecol Resour. https://doi.org/10.1111/1755-0998.12428

10. Brennan GL, Potter C, de Vere N, Griffith GW, Skjøth CA, Osborne NJ, Wheeler BW, Mclnnes RN, Clewlow Y, Barber A, Hanlon HM, Hegarty M, Jones L, Kurganskiiy A, Rowney FM, Armitage C, Adams-Groom B, Ford CR, Petch GM, Creer S (2019) Temperate airborne grass pollen defined by spatio-temporal shifts in community composition. Nat Ecol Evol 3:750-754. https://doi.org/10.1038/s41559-019-0849-7

11. Buchholz S, Gathof AK, Grossmann AJ, Kowarik I, Fischer LK (2020) Wild bees in urban grasslands: Urbanisation, functional diversity and species traits. Landsc Urban Plan 196:103731. https://doi.org/10.1016/j.landurbplan.2019.103731

12. Buchholz S, Kowarik I (2019) Urbanisation modulates plant-pollinator interactions in invasive vs. native plant species. Sci Rep 9:6375. https://doi.org/10.1038/s41598-019-42884-6

13. Callahan BJ, McMurdie PJ, Rosen MJ, Han AW, Johnson AJA, Holmes SP (2016) DADA2: High-resolution sample inference from Illumina amplicon data. Nat Methods 13:581-583. https://doi.org/10.1038/nmeth.3869

14. Cane JH (1987) Estimation of Bee Size Using Intertegular Span (Apoidea). J Kansas Entomol Soc 60:145-147

15. Cane JH, Sipes S (2006) Characterizing floral specialization by bees: analytical methods and a revised lexicon for oligolecty. In: Waser $\mathrm{N}$, Ollerton $\mathrm{J}$ (eds) Plant-pollinator interactions: from specialization to generalization. University of Chicago Press, Chicago, pp 99-122

16. Chen S, Yao H, Han J, Liu C, Song J, Shi L, Zhu Y, Ma X, Gao T, Pang X, Luo K, Li Y, Li X, Jia X, Lin Y, Leon C (2010) Validation of the ITS2 region as a novel DNA barcode for identifying medicinal plant species. PLoS ONE 5:e8613. https://doi.org/10.1371/journal.pone.0008613

17. Clarke KR, Gorley R (2015) PRIMER version 7: User manual/tutorial. PRIMER-E, Plymouth

18. Davies ZG, Fuller RA, Loram A, Irvine KN, Sims V, Gaston KJ (2009) A national scale inventory of resource provision for biodiversity within domestic gardens. Biol Conserv 142:761-771. https://doi.org/10.1016/j.biocon.2008.12.016

19. De Palma A, Kuhlmann M, Roberts SPM, Potts SG, Börger L, Hudson LN, Lysenko I, Newbold T, Purvis A (2015) Ecological traits affect the sensitivity of bees to land-use pressures in European agricultural landscapes. J Appl Ecol 52:1567-1577. https://doi.org/10.1111/1365-2664.12524

20. De Vere N, Jones LE, Gilmore T, Moscrop J, Lowe A, Smith D, Hegarty MJ, Creer S, Ford CR (2017) Using DNA metabarcoding to investigate honey bee foraging reveals limited flower use despite high floral availability. Sci Rep 7:42838. https://doi.org/10.1038/srep42838

21. Devictor V, Clavel J, Julliard R, Lavergne S, Mouillot D, Thuiller W, Venail P, Villéger S, Mouquet N (2010) Defining and measuring ecological specialization. J Appl Ecol 47:15-25. https://doi.org/10.1111/j.1365-2664.2009.01744.x

22. Dormontt EE, van Dijk K-J, Bell KL, Bigffin E, Breed MF, Byrne M, Caddy-Retalic S, Encinas-Viso F, Nevill PG, Shapcott A, Young JM, Waycott M, Lowe AJ (2018) Advancing DNA Barcoding and Metabarcoding Applications for Plants Requires Systematic Analysis of Herbarium Collections-An Australian Perspective. Front Ecol Evol 6:134. https://doi.org/10.3389/fevo.2018.00134

23. Filipiak ZM, Filipiak M (2020) The Scarcity of Specific Nutrients in Wild Bee Larval Food Negatively Influences Certain Life History Traits. Biology 9:462. https://doi.org/10.3390/biology 9120462

24. Fox LR, Morrow PA (1981) Specialization: species property or local phenomenon? Science 211:887-893. https://doi.org/10.1126/science.211.4485.887

25. Frøslev TG, Kjøller R, Bruun HH, Ejrnæs R, Brunbjerg AK, Pietroni C, Hansen AJ (2017) Algorithm for post-clustering curation of DNA amplicon data yields reliable biodiversity estimates. Nat Commun 8:1188. https://doi.org/10.1038/s41467-017-01312-x

26. Galimberti A, De Mattia F, Bruni I, Scaccabarozzi D, Sandionigi A, Barbuto M, Casiraghi M, Labra M (2014) A DNA barcoding approach to characterize pollen collected by honeybees. PLoS ONE 9:e109363. https://doi.org/10.1371/journal.pone.0109363

27. Gao J, O'Neill BC (2020) Mapping global urban land for the 21st century with data-driven simulations and Shared Socioeconomic Pathways. Nat Commun 11:2302. https://doi.org/10.1038/s41467-020-15788-7

28. Gous A, Eardley CD, Johnson SD, Swanevelder DZH, Willows-Munro S (2021) Floral hosts of leaf-cutter bees (Megachilidae) in a biodiversity hotspot revealed by pollen DNA metabarcoding of historic specimens. PLoS ONE 16:e0244973. https://doi.org/10.1371/journal.pone.0244973

29. Gresty CEA, Clare E, Devey DS, Cowan RS, Csiba L, Malakasi P, Lewis OT, Willis KJ (2018) Flower preferences and pollen transport networks for cavitynesting solitary bees: Implications for the design of agri-environment schemes. Ecol Evol 8:7574-7587. https://doi.org/10.1002/ece3.4234

30. Harrison T, Winfree R (2015) Urban drivers of plant-pollinator interactions. Funct Ecol

31. Hollingsworth PM, Graham SW, Little DP (2011) Choosing and using a plant DNA barcode. PLoS ONE 6:e19254. https://doi.org/10.1371/journal.pone.0019254

32. Houston T (2000) Native bees on wildflowers in Western Australia: a synopsis of native bee visitation of wildflowers in Western Australia based on the bee collection of the Western Australian Museum. Western Australian Museum, Western Australia 
33. Hung K-LJ, Ascher JS, Davids JA, Holway DA (2019) Ecological filtering in scrub fragments restructures the taxonomic and functional composition of native bee assemblages. Ecology 100:e02654. https://doi.org/10.1002/ecy.2654

34. Huson D (2018) User Manual for MEGAN V6.13.5. Version 6.13.5.

https://www.researchgate.net/profile/Daniel_Huson/publication/251816417_User_Manual_for_MEGAN_V35internal6/links/546cb2b10cf284dbf190e96f/ Manual-for-MEGAN-V35internal6.pdf

35. Johnson SD (2010) The pollination niche and its role in the diversification and maintenance of the southern African flora. Philos Trans R Soc Lond B Biol Sci 365:499-516. https://doi.org/10.1098/rstb.2009.0243

36. Keller A, Danner N, Grimmer G, Ankenbrand M, von der Ohe K, von der Ohe W, Rost S, Härtel S, Steffan-Dewenter I (2015) Evaluating multiplexed nextgeneration sequencing as a method in palynology for mixed pollen samples. Plant Biol 17. https://doi.org/10.1111/plb.12251

37. Krombein KV (1967) Trap-nesting wasps and bees. Washington, DC Smithsonian Inst Press, p 570

38. Maclvor JS (2017) Cavity-nest boxes for solitary bees: a century of design and research. Apidologie 48:311-327. https://doi.org/10.1007/s13592-016$0477-z$

39. McDonald RI, Colbert M, Hamann M, Simkin R, Walsh B (2018) Nature in the urban century: a global assessment of where and how to conserve nature for biodiversity and human wellbeing. The Nature Conservancy, Stockholm

40. McKinney ML (2002) Urbanization, Biodiversity, and Conservation: The impacts of urbanization on native species are poorly studied, but educating a highly urbanized human population about these impacts can greatly improve species conservation in all ecosystems. Bioscience 52:883-890. https://doi.org/10.1641/0006-3568(2002)052[0883:UBAC]2.0.C0;2

41. McMurdie PJ, Holmes S (2013) phyloseq: an R package for reproducible interactive analysis and graphics of microbiome census data. PLoS ONE 8:e61217. https://doi.org/10.1371/journal.pone.0061217

42. Menz MHM, Phillips RD, Winfree R, Kremen C, Aizen MA, Johnson SD, Dixon KW (2011) Reconnecting plants and pollinators: challenges in the restoration of pollination mutualisms. Trends Plant Sci 16:4-12. https://doi.org/10.1016/j.tplants.2010.09.006

43. Moorhouse-Gann RJ, Dunn JC, de Vere N, Goder M, Cole N, Hipperson J, Symondson WOC (2018) New universal ITS2 primers for high-resolution herbivory analyses using DNA metabarcoding in both tropical and temperate zones. Sci Rep 8:8542. https://doi.org/10.1038/s41598-018-26648-2

44. Murray DC, Coghlan ML, Bunce M (2015) From benchtop to desktop: important considerations when designing amplicon sequencing workflows. PLoS ONE 10:e0124671. https://doi.org/10.1371/journal.pone.0124671

45. O'Connor RS, Kunin WE, Garratt MPD, Potts SG, Roy HE, Andrews C, Jones CM, Peyton Jm, Savage J, Harvey MC, Morris RK, Roberts SP, Wright I, Vanbergen AJ, Carvell C (2019) Monitoring insect pollinators and flower visitation: The effectiveness and feasibility of different survey methods. Methods Ecol Evol 10:2129-2140. https://doi.org/10.1111/2041-210x.13292

46. Oksanen J, Guillaume Blanchet F, Friendly M, Kindt R, Legendre P, McGlinn D, Minchin PR, O'Hara RB, Simpson GL, Solymos P, Stevens HH, Szoecs E, Wagner H (2019) vegan: Community Ecology Package. Version 2.5-6 https://cran.ism.ac.jp/web/packages/vegan/vegan.pdf

47. Phillips RD, Hopper SD, Dixon KW (2010) Pollination ecology and the possible impacts of environmental change in the Southwest Australian Biodiversity Hotspot. Philos Trans R Soc Lond B Biol Sci 365:517-528. https://doi.org/10.1098/rstb.2009.0238

48. Pornon A, Andalo C, Burrus M, Escaravage N (2017) DNA metabarcoding data unveils invisible pollination networks. Sci Rep 7:16828. https://doi.org/10.1038/s41598-017-16785-5

49. Pornon A, Escaravage N, Burrus M, Holota H, Khimoun A, Mariette J, Pelizzari C, Iribar A, Etienne R, Taberlet P, Vidal M, Winterton P, Zinger L, Andalo C (2016) Using metabarcoding to reveal and quantify plant-pollinator interactions. Sci Rep 6:27282. https://doi.org/10.1038/srep27282

50. Prendergast K (2020) Plant-pollinator network interaction matrices, and flowering plant species composition, in urban bushland remnants and residential gardens in the southwest Western Australian biodiversity hotspot [Data set]. Plant-pollinator networks in Australian urban bushland remnants are not structurally equivalent to those in residential gardens. doi: $10.25917 / 5 \mathrm{f} 3 \mathrm{a} 0 \mathrm{aa} 235 \mathrm{fda}$

51. Prendergast K, Dixon KW, Bateman PW (2021) Interactions between the introduced European honey bee and native bees in urban areas varies by year, habitat type and native bee guild. Biol J Linn Soc Lond. https://doi.org/10.1093/biolinnean/blab024

52. Prendergast K, Menz MHM, Dixon KW, Bateman PW (2020) The relative performance of sampling methods for native bees: an empirical test and review of the literature. Ecosphere 11:206. https://doi.org/10.1002/ecs2.3076

53. Prendergast K, Ollerton J (2021) Plant-pollinator networks in Australian urban bushland remnants are not structurally equivalent to those in residential gardens. Urban Ecosyst. https://doi.org/10.1007/s11252-020-01089-w

54. Prodan A, Tremaroli V, Brolin H, Zwinderman AH, Nieuwdorp M, Levin E (2020) Comparing bioinformatic pipelines for microbial 16S rRNA amplicon sequencing. PLoS ONE 15:e0227434. https://doi.org/10.1371/journal.pone.0227434

55. R Core Team (2019) R: A Language and Environment for Statistical Computing. Version 3.6.1. R Foundation for Statistical Computing, Vienna, Austria. https://www.R-project.org/

56. Rader R, Bartomeus I, Tylianakis JM, Laliberté E (2014) The winners and losers of land use intensification: pollinator community disassembly is nonrandom and alters functional diversity. Divers Distrib 20:908-917. https://doi.org/10.1111/ddi.12221

57. Ritchie AD, Ruppel R, Jha S (2016) Generalist Behavior Describes Pollen Foraging for Perceived Oligolectic and Polylectic Bees. Environ Entomol 45:909919. https://doi.org/10.1093/ee/nvw032

58. Roulston TH, Cane JH (2000) The Effect of Diet Breadth and Nesting Ecology on Body Size Variation in Bees (Apiformes). J Kans Entomol Soc 73:129142 
59. Sánchez-Bayo F, Wyckhuys KAG (2019) Worldwide decline of the entomofauna: A review of its drivers. Biol Conserv 232:8-27. https://doi.org/10.1016/j.biocon.2019.01.020

60. Staab M, Pufal G, Tscharntke T, Klein A-M (2018) Trap nests for bees and wasps to analyse trophic interactions in changing environments-A systematic overview and user guide. Methods Ecol Evol 9:2226-2239. https://doi.org/10.1111/2041-210X.13070

61. Taberlet P, Coissac E, Hajibabaei M, Rieseberg LH (2012) Environmental DNA. Mol Ecol 21:1789-1793. https://doi.org/10.1111/j.1365294X.2012.05542.X

62. Taberlet P, Coissac E, Pompanon F, Gielly L, Miquel C, Valentini A, Vernat T, Corthier G, Brochmann C, Willerslev E (2007) Power and limitations of the chloroplast trnL (UAA) intron for plant DNA barcoding. Nucleic Acids Res 35:e14-e14. https://doi.org/10.1093/nar/gkl938

63. Threlfall CG, Walker K, Williams NSG, Hahs AK, Mata L, Stork N, Livesley SJ (2015) The conservation value of urban green space habitats for Australian native bee communities. Biol Conserv 187:240-248. https://doi.org/10.1016/J.BIOCON.2015.05.003

64. Torchio PF, Tepedino VJ (1980) Sex ratio, body size and seasonality in a solitary bee, Osmia lignaria propinqua cresson (Hymenoptera: Megachilidae). Evolution 34:993-1003. https://doi.org/10.1111/j.1558-5646.1980.tb04037.x

65. Tscharntke T, Gathmann A, Steffan-Dewenter I (1998) Bioindication using trap-nesting bees and wasps and their natural enemies: community structure and interactions. J Appl Ecol 35:708-719. https://doi.org/10.1046/j.1365-2664.1998.355343.x

66. Voulgari-Kokota A, Ankenbrand MJ (2019) Linking pollen foraging of megachilid bees to their nest bacterial microbiota. Ecol Evol 9:10788-11800. https://doi.org/10.1002/ece3.5599

67. Wcislo WT, Cane JH (1996) Floral resource utilization by solitary bees (Hymenoptera: Apoidea) and exploitation of their stored foods by natural enemies. Annu Rev Entomol 41:257-286. https://doi.org/10.1146/annurev.en.41.010196.001353

68. Wenzel A, Grass I, Belavadi VV, Tscharntke T (2020) How urbanization is driving pollinator diversity and pollination--A systematic review. Biol Conserv 241:108321

69. Wickham H (2016) ggplot2: Elegant Graphics for Data Analysis. Springer-Verlag, New York. https://ggplot2.tidyverse.org

70. Wilkinson SP, Davy SK, Bunce M, Stat M (2018) Taxonomic identification of environmental DNA with informatic sequence classification trees. PeerJ Preprints. doi:10.7287/peerj.preprints.26812v1

71. Wilson RS, Keller A, Shapcott A, Leonhardt SD, Sickel W, Hardwick JL, Heard TA, Kaluza BF, Wallace HM (2021) Many small rather than few large sources identified in long-term bee pollen diets in agroecosystems. Agric Ecosyst Environ 310:107296. https://doi.org/10.1016/j.agee.2020.107296

72. Winfree R, Williams NM, Gaines H, Ascher JS, Kremen C (2008) Wild Bee Pollinators Provide the Majority of Crop Visitation across Land-Use Gradients in New Jersey and Pennsylvania, USA. J Appl Ecol 45:793-802

73. Wright IR, Roberts SPM, Collins BE (2015) Evidence of forage distance limitations for small bees (Hymenoptera: Apidae). Eur J Entomol 112:303-310. https://doi.org/10.14411/eje.2015.028

74. Yao H, Song J, Liu C, Luo K, Han J, Li Y, Pang X, Xu H, Zhu Y, Xiao P, Chen S (2010) Use of ITS2 region as the universal DNA barcode for plants and animals. PLoS ONE. https://doi.org/10.1371/journal.pone.0013102

75. Zurbuchen A, Cheesman S, Klaiber J, Müller A, Hein S, Dorn S (2010a) Long foraging distances impose high costs on offspring production in solitary bees. J Anim Ecol 79:674-681. https://doi.org/10.1111/j.1365-2656.2010.01675.x

76. Zurbuchen A, Landert L, Klaiber J, Müller A, Hein S, Dorn S (2010b) Maximum foraging ranges in solitary bees: only few individuals have the capability to cover long foraging distances. Biol Conserv 143:669-676. https://doi.org/10.1016/j.biocon.2009.12.003

\section{Figures}

\section{Figure 1}

A) Map of the study sites in Perth, Western Australia showing locations of bushland remnant (grey circle) and residential garden (black triangle) habitat types with images of bee species included in this study alongside. Species in the blue box are polylectic (generalists) whilst those in the orange box are oligolectic (specialists). Images of bees were taken by K.S. Prendergast using the WA Museum's imaging microscope and stacking software. B) Bee visitor to a trap nest. Image by K.S Prendergast. C) Inside a M. fabricatornesting tube showing four mature adults, larvae, a parasitic bombyliid Anthrax sp. fly, and the remaining pollen and plant material debris. Images by K.S Prendergast. 


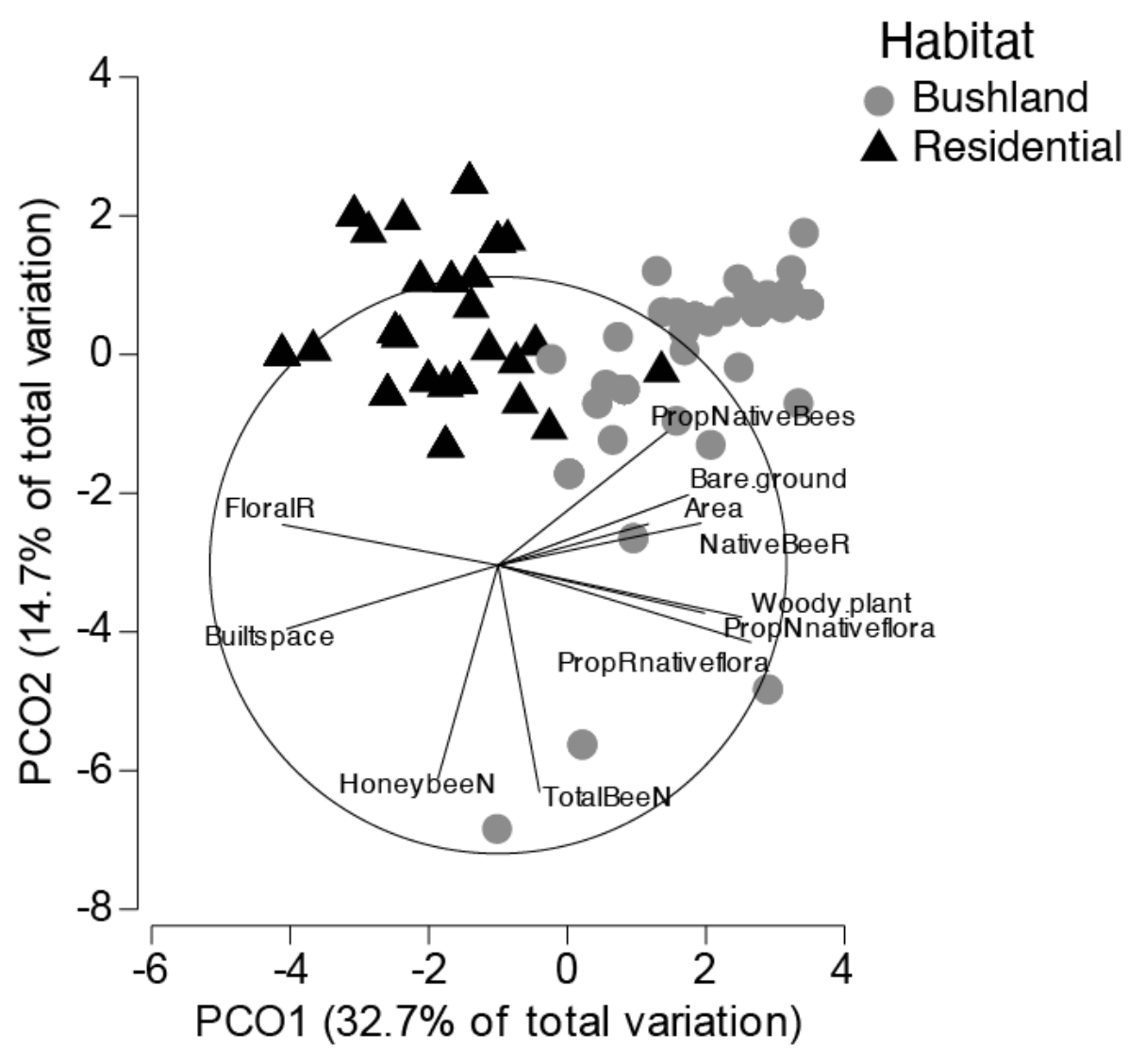

Figure 2

Principal Coordinates Analysis (PCO) plot of the measured habitat characteristics between bushland remnant (grey circle) and residential garden (black triangle) habitat types. The vectors plotted illustrate the strength and direction of the correlations of habitat characteristics to the PCO axes that were greater than 0.5. For descriptions of abbreviations of habitat characteristics see Supp. Table 2. 
A)

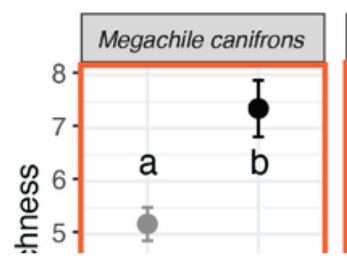

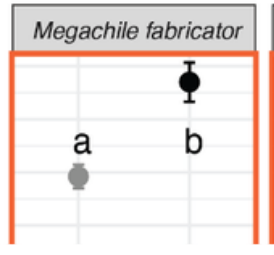

B)

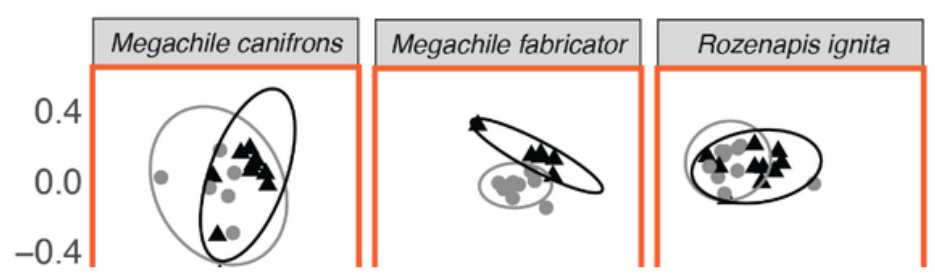

Figure 3

A) Square-root transformed mean observed ASV richness ( \pm S.E.) of plant taxa detected within nesting tubes for each species of bee and bushland remnant (grey circle) and residential garden (black circle) habitat type. Lowercase letters indicates pairwise significant difference ( $a=0.05)$. B) Non-metric Multidimensional Scaling (NMDS) plot with Jaccard Similarity showing species of bees and the forage composition of nesting tubes between those in bushland remnant (grey circle) and residential garden (black triangle) habitat type. 95\% confidence intervals illustrated with circles corresponding to colour of bushland remnants (grey) and residential gardens (black). Species in the blue box are polylectic (generalists) whilst those in the orange box are oligolectic (specialists).

\section{Supplementary Files}

This is a list of supplementary files associated with this preprint. Click to download.

- SupplementaryMaterials.docx 